\title{
Child Tracking System
}

\author{
Fairuz Rauf \\ Faculty of Communication \\ Visual Art and Computing \\ Universiti Selangor \\ Malaysia
}

\author{
Gothiswary Subramaniam \\ Faculty of Communication \\ Visual Art and Computing \\ Universiti Selangor \\ Malaysia
}

\author{
Zuraidy Adnan \\ Faculty of Communication \\ Visual Art and Computing \\ Universiti Selangor \\ Malaysia
}

\begin{abstract}
Child tracking system is an app that can track and monitor the child location. The aim of the project is to create a system to allow the parents to keep track of their kids when their child is out of their view. However, with the child tracking system the parent can track and monitor their child location in just a simple app when the parent is in office. A study on few existing tracking system have been done to gather the information and existing problem. Methodology applied in this project is Rational Unified Process (RUP) model. Data collection method which are questionnaire and interview also conducted to gather the user requirements and needs for the system. The result have been analysed based on user responses. Most of the user (parents) agree and looking forward the system to be implemented.
\end{abstract}

\section{Keywords}

GPS, tracking, mobile

\section{INTRODUCTION}

The child is a creature that makes their life become more joyful and meaningful. However, parents cannot take care of their child from every moment. As the days went past, the child will be grown up and starting their school life. The parent is not possible to always stay beside of them as most of the parents needs to go for work to earn some income to sustain a family. Today's child is easier influenced by their friends, and they might even get cheated or kidnapped by any of the strangers.

In Malaysia the crime rate become increasing day by day. Of all the crimes, kidnapping is the worst one. While it poses a great threat to the victim's life, it also causes endless mental agony and sleepless nights to the others at home. One of kidnappers target is making money by kidnap the children and use them to make pornography films and distribute it.

There are few cases happens in Malaysia. Based on The Star newspaper, police should prioritized the cases of missing children as they could be linked to human trafficking (Deputy Home Minister Datuk Masir Kujat, Thursday, 24 Mar 2016). Based on The Star newspaper, a 17-year-old boy was abducted from his home in Taiping, blindfolded, bound and taken to Butterworth, Penang, some $90 \mathrm{~km}$ away and kidnappers demanded a RM3mil ransom and threatened to kill the boy if it was not paid (Perak Police Chief Comm Datuk Hasnan Hassan, Thursday, 21 Sep 2017).

This project focused on how parents can keep track their children movement to avoid child missing, kidnapping and etc. By using GPS as a tracking tool where it allows to determine the exact location (longitude and latitude) of the children. Every an hour, the location of the children will be recorded in the system to keep track the children.

\subsection{Background of Study}

People cannot predict or determine what will happen next to them in next seconds. This is the same scenario as people cannot acknowledge of when will be targeted, but can make precaution prevent it from happening. As for the great parents, their greatest concerns are their child, especially regarding the safety of the child. The parents start to take care of the child since born. The parent is not possible to always stay beside of them as most of the parents needs to go for work to earn some money to sustain a family. Parents will start to feel anxious about their child current status every second because they cannot see what their child is doing currently or what affairs will happen on them.

Today's child is easier influenced by their friends, and they might even get cheated or kidnapped by any of the strangers, as what had happened to a girl, named Nurlin Jazlin, who had gone missing on August 20, 2007 after she went alone at a night market in Kuala Lumpur. She was found dead in a sports bag after a month of investigation by police (Theage.com.au, 2016). To minimize this tragedy from happening again, an action needs to be taken to deal with the problem. Thus, in order to resolve these problems the child tracking system is proposed.

\subsection{Problem Statement}

1) Increasing rate of child kidnapping.

- According to News Strait Times Newspaper, of the 567 children, another 193 children are still missing and being investigated. A majority of cases were due to family problems, seeking freedom and running off with lovers or friends. (Bukit Aman CID (Investigations and Legal) deputy director Datuk Law Hong Soon, June 4, 2016)

2) Lack of tracking technology for child.

- The parent is hardly to keep a watch on their child without the use of technology, especially when the child is in the outdoor. The parent even cannot avoid the negligence that will make by children in the future day.

3) Limited application for child monitoring.

- There are very limited application available for tracking child when they are out of parents control and let kidnapping or missing cases occurred.

\subsection{Objectives}

The objectives of developing this system were:

1) To reduce child kidnapping through introduction of the tracking system.

- $\quad$ The parent is not possible to always stay beside of children as most of the parents needs to go for work. By having this child tracking system, parents can track the location of their children.

2) To propose tracking technology for child tracking system

- Using GPS as a tracking tool where it allows to determine the exact location (longitude and latitude) of 
the children. The technology can allow parents to track child whereabouts.

3) To develop a Child Tracking System.

- Parent can keep track their children movement when they were at outdoor and also current location of the child.

\subsection{Scope}

To ensure the project running smoothly a few scope have listed as a guide to achieve project objectives. There are few scopes are discussed below:

\section{User Scope}

This project is actually developed for parents to keep track the child whereabouts. Nowadays, child is easier influenced by their friends, and they might even get cheated or kidnapped by any of the strangers. By developing this system can track child current location.

\section{System Scope}

The application will deal with the Android platform and is utilized for GPS following between different mobile devices. The application is mindful to keep track the location of the device. The parent or child account can be edit by parents. The application will include the route history trace where the parent track for the route their child traversed during a certain period of time. The application in the device will update the location of the child to the application by having the interval time for 30 min, 1 hour and 2 hour. Parent can select the interval time to view the current location of the child. Parent also can make call from the application if any inconvenience happens when the location not found or track.

\subsection{Significance of project}

Nowadays crime rate are increasing day by day especially kidnapping child. Moreover, parents is not possible to always stay beside of them as most of the parents needs to go for work to earn some money to sustain a family. The proposed of the system can reduce the child missing cases. This system provide tracking solution for the parent to keep tracking their child location in the outdoor by using GPS as where it allows to determine the exact location of the child. Moreover, help to minimize this tragedy from happening again and again in future.

\section{LITERATURE REVIEW}

This chapter briefly describes the review on existing techniques related with the propose project. In this topic, this literature review will discuss about the tracking system. This literature review is a summary and explanation of the complete and current state of knowledge on limited topics as found in journal articles. In this chapter, only three system are compared for tracking system.

There are a large number of studies of the tracking system in the different areas. However, since the focus of this research is on the child tracking system, these will not be reviewed in detail and will only be referred to as appropriate. Studies are performed on three existing system which are FiLIP, TraxPlay and PockeyFinder

Besides, studies are also performed on technologies involved and methodology applies in the proposed system that will act as a guidance in practicing the best approach for building the tracking system for child.

\subsection{Technology}

There are many tracking technology can be used to develop the system. Studies had been done on the available technology that can be used in the proposed system. Below shows the hardware and software that use in the proposed system.

Android gives a world-class platform for creating apps and games for Android users everywhere, as well as an open marketplace for distributing to them instantly. Android gives everything that need to build best-in-class app experiences. It gives a single application model that lets deploy apps broadly to hundreds of millions of users across a wide range of devices from phones to tablets and beyond.

Android also gives tools for creating apps that look great and take advantage of the hardware capabilities available on each device. It automatically adapts UI to look its best on each device, while giving as much control as people want over UI on different device types. For example, can create a single app binary that's optimized for both phone and tablet form factors (Google Android, 2015).

GPS is a system which is already implemented and everyone can access it without any restriction. GPS works in any weather conditions, anywhere in the world, 24 hours a day. There are no subscription fees or setup charges to use GPS. GPSs are very quickly becoming a standard in most new automobiles, and are even finding their way onto a variety of new cell phones. The mapping devices can come in handy under a variety of circumstances. Benefit of having GPS is GPS can help us to determine exactly where we are at any given moment. Not only can a GPS give the name of the street might be traveling on, but many GPS systems can also give us the exact latitude and longitude of where you are located (Md. Palash Uddin, Md. Zahidul Islam, Md. Nadim, 2013).

Android software development is the process by which new applications are created for the Android devices operating system. It is purpose built for Android to accelerate your development and help you build the highest-quality apps for every Android device. It is available for download on Windows, MacOS and Linux based operating systems. Applications are usually developed in Java programming language using the Android software development kit (SDK) (M.David, 2015).

\section{INTRODUCTIONS}

The process used to collect data and information for the purpose of making decision. Methodology includes research, questionnaire, interviews, observation, survey, case studies and etc. suitable methodology should be identify for the successful implementation of system since involves development process and phases.

The aim of the research is to collect data and information from the user (parents) by direct interview session and distribute the questionnaire about proposed system which is Child Tracking System. By conducting this method some problem could be clarified. This research will be focus on analyze user requirement by using Rational Unified Process (RUP).

\subsection{Data Collection Methods}

Information gather can come from a range of sources. There are variety of techniques to use when gathering primary data and information. The method used to propose system are interview and questionnaire. The questionnaire are distributed to several parents through by hand since this system proposed for parents themselves. The result from the questionnaires collect generate it into graph. Interview is involves direct questioning to certain parents. 


\subsubsection{Interview}

Interview are among the most familiar strategies for collecting data (DiCicco Bloom etc al., 2006). There are variety ways for interviewing such as by phone interview, video interview, face to face interview and etc. Information for the development of this project, face to face interview session needs to be conduct. The interview questions (refer Appendix C) have been prepared to get response from the user who is parents. Purpose of the interview is to gather information about the user requirements for this project.

\subsubsection{Questionnaire}

The questionnaire is a well establish tool within social science research for acquiring information on participant social characteristics, present and past behavior, standard of behavior or attitudes and their beliefs and reasons for action with respect to the topic under investigation (Bulmer, 2004). Questionnaire (refer Appendix B) is one of the simplest and useful tool to obtain information and opinion from various user (parents). Questionnaire also very useful to collect data for developing Child Tracking System. Questionnaire will distribute to parents for data collection regarding the proposed system with targeted 20 respondents.

\subsection{Data Analysis Method}

In this project, all the data were collected from user (parents) will be analyze to get the solution for the problem and design the solution they need as the information gather from interview and questionnaire. The method for analyze data is by using Google Docs. Google Docs can import, create, edit and update documents in various fonts and file formats, combining text with formulas, lists, tables and images. By using Google Docs, the questionnaire has been done smoothly. Using Google Docs can analyze the result by statistics, pie chart, graph and comment.

\subsection{Software Development Methods}

This proposed system will be using Rational Unified Process (RUP). RUP is an Object-Oriented, and Web-Enabled system development methodology. RUP goal is to ensure the production of high-quality software that meets the needs of its end-users, within a predictable schedule and budget (Ashraf Anwar, 2014). RUP establishes four phases of development. Figure 1 shows the steps and methods used in RUP. RUP is like an online mentor that provides guidelines, templates, and examples for all aspects and stages of development.

Table 1: Advantages and Disadvantages of Rational Unified Process (RUP)

\begin{tabular}{|l|l|}
\hline Advantages & Disadvantages \\
\hline Efficient use of resources & $\begin{array}{l}\text { The process may be too complex } \\
\text { to implement }\end{array}$ \\
\hline $\begin{array}{l}\text { Deliver exactly what the } \\
\text { customer wants }\end{array}$ & It is a heavyweight process \\
\hline $\begin{array}{l}\text { Issues discovered early in } \\
\text { the project }\end{array}$ & $\begin{array}{l}\text { Development can get out of the } \\
\text { control }\end{array}$ \\
\hline Improve risk management & $\begin{array}{l}\text { Need expert to fully adopt the } \\
\text { process }\end{array}$ \\
\hline
\end{tabular}

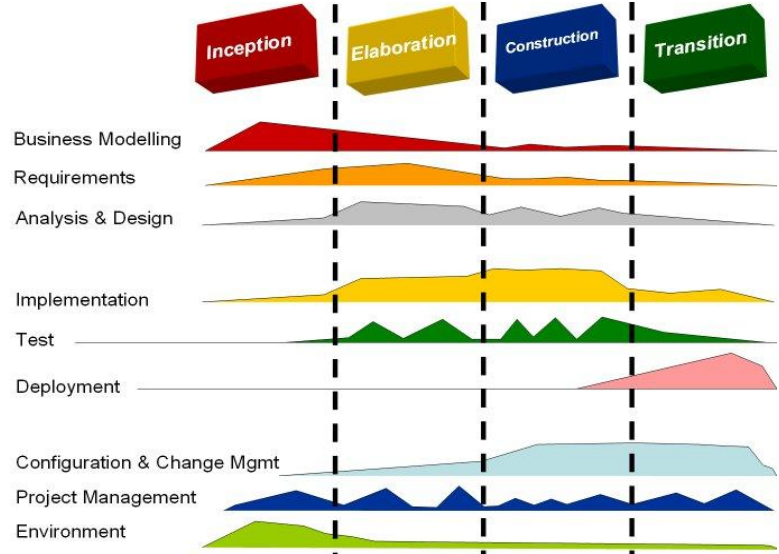

Figure 1: RUP Model

\section{INTRODUCTIONS}

This chapter will cover on analysis of the data collected in terms of pie charts and graphs. It contains user requirements and system requirements. The requirements was collected based on interview and questionnaire during the study research. The interview section was conducted with selected five parents and also questionnaire has been given to parents to gather the information as in questions and also the expectation view on the proposed system.

\subsection{User requirement}

The main target of user for this proposed system is parents itself. All the flow of the tracking and monitoring child is collected during interview session. The user requirement for this system was collected in questionnaire.

\subsubsection{Survey analysis}

Survey have been carry out by sending out the questionnaire to the target group of parent and also interviewing a group of parents. The objective of carry out the survey is to get the user requirements and opinions about the child tracking system. The results based on the 24 responses are collected and being analyzed.

\section{INTRODUCTIONS}

System design is one of the most important things that developer has to do before developing a system. A good system design may give a good start up and able to cope with system requirements. In this chapter, system design is described in detail. Interface design of the system will be designed. Several techniques are used to model the design of the proposed system, including architecture diagram, system design (use case diagram, sequence diagram, class diagram, state diagram) and database design (ERD diagram for the database design and data dictionary)

\subsection{Architecture Design}

The architecture design showed the elements involved in proposed system. There are generally 2 users involved which is the parent application and child application, for example, the parent sends a request to the server for the location of the child, and the server will send the request to the child app about the request. When the request received and location retrieved, the child app will send the request again to the server about the newly detected location. The server then will send the details to alert the parent about the new location and show the latest location inside the map of the app. The diagram is shown in Figure 2. 


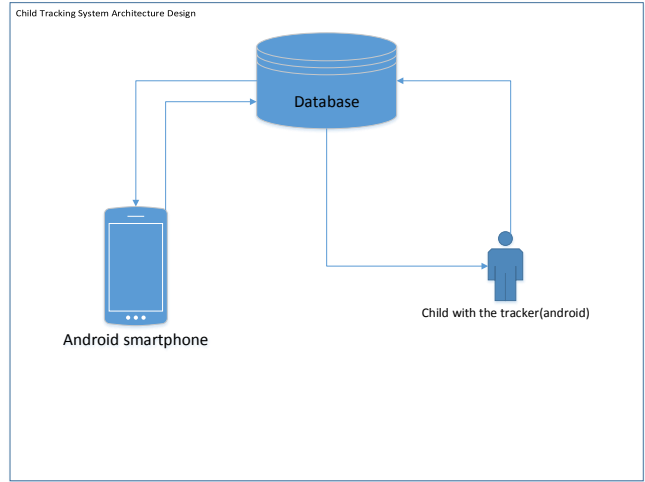

Figure 2: Architecture Design

\section{CONCLUSION}

Malaysian parent, especially who live in urban area, needed to work day and night to sustain the family which causes them cannot know where their child is going during the working hour. However, with the child tracking app, parent can track and monitor their child with just a simple app. The parent is not possible to always stay beside of children as most of the parents needs to go for work. By having this child tracking system, parents can track the location of their children. In order to avoid the kidnapping cases, the child tracking system is needed.

\section{REFERENCES}

[1] (Android \& Google, 2016)Android, \& Google. (2016). Android Studio Features | AndroidStudio. Android. Retrieved from https://developer.android.com/studio/features.html

[2] (El-rabbany, 2006)El-rabbany, A. (2006). Introduction to GPS: The Global Position System. NavtechGPS Part 1221. https://doi.org/10.2493/jjspe.72.285

[3] FiLIP, 2016. FiLIP - THE WORLD'S FIRST SMART LOCATOR AND PHONE FOR KIDS. [online] Available at: http://www.myfilip.com/ [Accessed 2 Nov. 2017].

[4] (Gestwicki \& Ahmad, 2011)Gestwicki, P., \& Ahmad, K. (2011). App Inventor for Android with Studio-based
Learning. J. Comput. Sci. Coll., 27(1), 55-63. Retrieved from http://dl.acm.org/citation.cfm?id=2037151.2037164

[5] (Omer \& Abdullah, 2013)Omer, E., \& Abdullah, M. F. A. (2013). GPS and SMS-Based Child Tracking System Using Smart Phone. Internasionala Journal of Electrical, Computer, Electronic and Communication Engineering, 7(2), 171-174.

[6] (Pawade \& Gaikwad, 2015)Pawade, R. H., \& Gaikwad, A. N. (2015). Android Based Children Tracking System, 4(6), 2088-2092.

[7] (Pham, Drieberg, \& Nguyen, 2013)Pham, H. D., Drieberg, M., \& Nguyen, C. C. (2013). Development of vehicle tracking system using GPS and GSM modem. In 2013 IEEE Conference on Open Systems, ICOS 2013 (pp. 8994). https://doi.org/10.1109/ICOS.2013.6735054

[8] (Rycroft, 1997)Rycroft, M. J. (1997). Understanding GPS. Principles and applications. Journal of Atmospheric and Solar-Terrestrial Physics, 59(5), 598-599. https://doi.org/10.1016/S1364-6826(97)83337-8

[9] (Sarjana \& Ii, 2012)Sarjana, P., \& Ii, M. (2012). GSM \& GPS BASED SCHOOL KIDS TRACKING SYSTEM NG WOON CEA This Report Is Submitted In Partial Fulfilment of Requirements for the Award of Bachelor Degree of Electronic Engineering ( Industrial Electronic ) With Honours Faculty of Electronic Engineering.

[10] (Salihoglu \& Widom, 2013)Salihoglu, S., \& Widom, J. (2013). Gps. Proceedings of the 25th International Conference on Scientific and Statistical Database Management SSDBM, https://doi.org/10.1145/2484838.2484843

[11] (Satish, Nandlal, \& Sandip, 2015)Satish, M., Nandlal, C., \& Sandip, G. (2015). Child Tracking System using Android phones, 4(4), 1257-1260.

[12] Traxfamily.com, 2016. Trax-Home | by WTS. [online] Available at: http://www.traxfamily.com/ [Accessed 2 Nov. 2017]. 